điều trị, trong việc nổ lực giảm tỷ lệ dịch truyền ở bệnh nhân sốc sốt xuất huyết dengue, nhưng lượng dịch cũng không giảm, điều đó cho thây sinh bệnh học của sốt xuất huyết dengue là tình trạng thoát huyết tương, và việc bù dịch điều trị là vô cùng quan trọng.

\section{KẾT LUÂN}

Trẻ sốc sốt xuất huyết dengue nhập bệnh viện nhi đồng 1 từ sớm vẫn có tỷ lệ tổn thươnng cớ quan cao và tổng lượng dịch truyền của trẻ cũng còn rất nhiều.

\section{TÀI LIÊU THAM KHẢO}

1. World Health Organization, Research Special Programme for, Diseases Training in Tropical, et al. (2009), Dengue: guidelines for diagnosis, treatment, prevention and control, World Health Organization,Bộ Y tế (2019), "Hướng dẫn chẩn đoán, điều trị sốt xuất huyết dengue", Hà Nội.

2. Halstead S. B. (1988), "Pathogenesis of dengue: challenges to molecular biology", Science, 239(4839), pp. 476-81.
3. Lương Anh Tuấn (2007), Mối liên quan giữa tình trạng béo phì với đặc điêm lâm sàng và điều trị trong sốc sốt xuất huyết dengue ở trẻ từ 2 đến 15 tuổi, Luận văn Bác sĩ chuyên khoa cấp II, Đại học Y dước TंP. Hồ Chí Minh.

4. Huỳnh Nguyễn Duy Liêm (2009), Đặc điểm dịch tễ, lâm sàng, cân lâm sàng và điêu trị ở trẻ em bi sốc sốt xuất huyết có rối loan đông máu, Luân văn Thạc sĩ Y học, Đai học Y dược TP. Hồ Chí Minh.

5. Văn Thi Cẩm Thanh (2017), Đăc điểm dich tễ, lâm sàng, cận lâm sàng và điều trị bệnh nhân sốt xuất huyết dengue nặng có sốc tại bệnh viện Nhi đồng 2. Luân văn thac sĩ y hoc, Đai học Y dước TPHCM.

6. Ngô Thị Thanh Thừy (2010), Đặc điểm rối loạn chức năng gan và rối loạn đông máu trên bệnh nhân sốt xuất huyết dengue điều trị tai bệnh viện Nhi đồng 2, Luận văn tốt nghiệp Bác sĩ nội trú, Đại học Y dược TP. Hồ Chí Minh.

7. Nguyển Minh Tiến (2005), Tổn thương các cơ quan trong sốc sốt xuất huyết Dengue kéo dài ở trẻ em, Luâan án Bác sỹ chuyên khoa II, Đại học Y dược TP Hồ Chí Minh.

8. Tạ Văn Trâm, Hoàng Trong Kim và Nguyễn Trọng Lân (2003), "Các yểu tố liên quan đến sốc sốt xuất huyết Dengue kéo dài ở trẻ em", Tạp chí Nhi khoa, 11(1), tr. 64-70.

\title{
PHẪU THUẬT U XƠ MACH VÒM MŨI HỌNG XÂM LẤN VÙNG XOANG HANG VÀ NộI Sọ
}

\author{
Trần Hạnh Uyên*, Nguyễn Thị Phương Lam*, Lê Thị Anh Thu*,
} Nguyễn Ngọc Khang*, Trần Minh Trường*

\section{TÓM TẮT}

Mục tiêu: Báo cáo hôi cứu và phân tích dấu hiêu về lâm sàng, hình ảnh học, kết quả điều trị của JNA xâm lấn vào trong sọ. Đường đi của u khi xâm lấn vào sọ, tần suất bệnh xầm lấn vào sọ và ảnh hưởng của các biện pháp điều trị được bàn luận. Đối tượng và phương pháp nghiến cứu: Trong nghiên cứu này chúng tôi hồi cứu 5 ca bệnh JNA xâm lấn vào nội so tuổi từ 13 đến 28. trong thời gian từ 2018-2021. Kết quả: Theo phân loại của Session 5 bênh nhân được phân loại giai đoạn III, xâm lấn vào trong sọ là 2 ca và ngoài sọ vừng xoang hang là $3 \mathrm{ca}$. Tất cả bệnh nhân được phẫu thuật cắt $u$ và thực hiện qua đường Degloving "lột găng" và Trước tai dưới hố thái dương hoặc phối hợp. Nội soi được sự dụng hố trợ khi cần thiết. Thời gian theo dõi sau phẫu thuật là 2 năm. Kết luận: U có thể phát triển xâm lấn vào sọ qua các khe hoặc lỗ tự nhiên để vào phía trong vùng nền sọ đăc biệt là vị trí khe ổ mắt trên. Do nguy cơ phẫu thuật, tái phát và biến chứng nên các khối u lan rộng cần được điều trị bởi kíp các bác sĩ nhiều chuyên khoa với

*Bệnh viện Chợ Rẫy

Chịu trách nhiệm chính: Trân Hạnh Uyên

Email: uyenent@gmail.com

Ngày nhận bài: 14.9.2021

Ngày phản biên khoa học: 4.11 .2021

Ngày duyệt bài: 15.11.2021 các kỹ thuật và phương tiện điều trị hiện đại và thích hợp.

\section{SUMMARY \\ SURGICAL APPROACH FOR JUVENILE ANGIOFIBROMA WITH INTRACRANIAL EXTENSION}

Introduction: Middle skull base and infratemporal fossa are the most complex anatomical structure and difficult to approach. Tumors in this area are very diverse, located close to other critical neurovascular structures, therefore, surgical approach to remove tumors is always a challenge. Objective: The article review clinical symptoms, radiological images and outcomes of surgical approach to remove JNA tumors with middle cranial fossa and cavernous sinus extension. Pathway for tumor invade the the middle cranial fossa and its incidence at otorhinolaryngology department of Cho Ray hospital. Methods: The study is a case series to review 05 patients (ages 13 to 28) diagnosed with JNA tumor with intracranial extension from 2018 - 2021. Results: All 5 patients with JNA was diagnosed with stage III. All of them were treated with Degloving approach and Preauricular Subtemporal Infratemporal Fossa approach or combining those techniques. Endoscopic surgery was used as additional technique. Follow up was 2 years. Conclusion: Tumor can invade middle cranial fossa and cavernous sinus through natural fissure and 
foramen, most commonly is superior orbital fissure. Due to high risk of complications and recurrence, the extensive tumor should be treated by a multidisciplinary team and modern techniques.

\section{I. ĐẶT VẤN ĐỀ}

U xơ mạch vòm mũi họng tuổi dậy thì (JNA) là u lành tính, tiến triển chậm, giàu mạch máu, không thường gặp và chỉ xảy ra ở trẻ nam tuối trung bình là 14 . U có tần suất $0.05 \%$ trong các loại u vùng đầu cổ và phát triển xâm lấn lan rộng bằng cách ăn mòn xương và xâm lấn các cấu trúc mô mềm xung quanh $[1,2]$. 75\% bệnh nhân có biểu hiện chảy máu mũi và nghẹt mũi hàng tháng thậm chí hàng năm. Trong bài này chúng tôi trình bày 5 trường hợp u xâm lấn vào não và xoang hang với các biểu hiện lâm sàng gồm nghẹt mũi kéo dài và có kèm theo chảy máu mũi hoặc có kèm theo triệu chứng nghi ngờ khi một bên mă̆t của bệnh nhân sưng lên, lồi mắt, hoặc tiến triển thàm lặng trong một thời gian dài trước khi được phát hiện và chẩn đoán chỉ dựa chủ yếu vào hình ảnh học. Để chọn đường phẫu thuật phù hợp cần sự hiểu biết về đường đi lan rộng của u cũng như tuỳ thuộc vào vị trí, kích thước u và hiểu biết chính xác giải phẫu khu vực phẫu thuật [5]. Mục tiêu nghiên cứu

1. Đặc điểm của bênh nhân u xơ vòm có xâm lấn xoang hang hay nội sọ.

2. Phẫu thuật cắt bỏ u xơ mạch qua đường mũi xoang và đường trước tai dưới thái dương.

\section{3. Đánh giá kêt quả phẫu thuật}

\section{II. ĐỐI TƯỢNG VÀ PHƯƠNG PHÁP NGHIÊN CỨU}

Nghiên cứu hồi cứu 5 trường hợp u xơ mạch vòm mũi họng xâm lấn vào sọ não và xoang hang được chẩn đoán và điều trị tai khoa tai mũi họng bệnh viện Chợ Rẫy từ tháng 01/2018 đến tháng 10/2021. Kết quả lâm sàng, hình ảnh học, phẫu thuật cũng như giải phẫu bệnh lý được được ghi nhận và xem xét chi tiết.

\section{Phương pháp tiến hành}

\section{a. Chuẩn bỉ bênh nhân:}

- Làm các xét nghiệm cận lâm sàng tiên phẫu, chú ý tình trạng mất máu mãn tính và suy dinh dưỡng của bệnh nhân; Nội soi mũi họng đánh giá khối u; Chụp CT scan và MRI

- Giải thích cho bênh nhân và người nhà về những tai biến và biến chứng có thể xảy ra trong và sau khi phẫu thuật.

- Chụp DSA khảo sát các mạch máu nuôi và làm tắc mạch trước khi phẫu thuật 1-2 ngày.

- Kíp mổ gồm bác sĩ tai mũi họng và ngoại khoa thần kinh, làm việc trong lĩnh vực của chuyên môn

- U được phân loại giai đoạn theo phân loại

\section{của Session}

\section{b. Tiến hành phẫu thuật:}

Đường mổ đã được áp dụng: Đường mổ trước tai dưới thái dương được hoặc đường dưới rãnh lợi môi xuyên xoang hàm hoặc phối hợp 2 đường mổ.

Bệnh nhân gây mê toàn thân

Các bước phẫu thuật chủ yễu của đường trước tai dưới thái dương như sau :

- Rạch da trước tai, cắt vén cân thái dương xuống dưới, cắt cung gò má, lồi cầu ổ khớp xương hàm

- Cắt xương của nền sọ kích thước nhỏ để vào hố sọ giữa, đáy sọ. Cầm máu bằng Bipolar

- Vén màng não, não và đi vào cắt khối u.

- Khâu lại màng não, cân thái dương, cung gò má. Không cần dẫn lưu dịch tuỷ sống

- Số lượng máu mất được ước lượng qua lượng dịch hút vào bình của máy hút

Đường mổ Degloving: rạch niêm mạc rãnh lợi môi đi vào trong hốc mũi cắt vách ngăn và lây u xơ mạch như các trường hợp khối u hốc mũi của tai mũi họng.

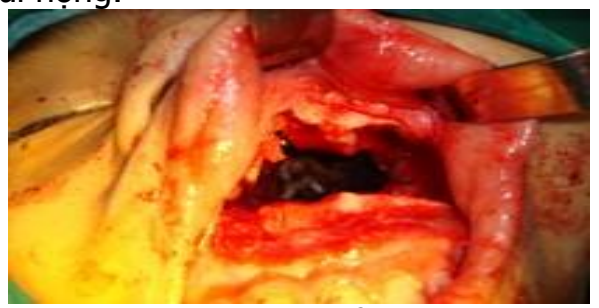

Hình 1. Đường mổ Degloving

Sau mổ bệnh nhân được sử dụng kháng sinh toàn thân phổ rộng (thường dùng nhóm Cephalosporin), kháng viêm và theo dõi các dấu hiệu sinh tồn, sau 1 tuần nễu ổn định có thể cho xuất viện và tái khám định kỳ theo lịch.

\section{KẾT QUẢ NGHIÊN CứU}

\section{Tình hình bệnh nhân}

Số bệnh nhân: - nam: 5 (100\%) Tuổi: 13-28

Bảng 1: Các triệu chứng lâm sàng (5 bệnh nhân)

\begin{tabular}{|c|c|c|c|c|c|c|c|}
\hline $\begin{array}{c}\text { Nghet } \\
\text { mũít }\end{array}$ & $\begin{array}{c}\text { Cháy máu } \\
\text { mưi }\end{array}$ & $\begin{array}{c}\text { Nhức } \\
\text { đâuu }\end{array}$ & $\begin{array}{c}\text { Đaaŭ } \\
\text { mặt }\end{array}$ & $\begin{array}{c}\text { Sưng biến } \\
\text { dạng mặt }\end{array}$ & $\begin{array}{c}\text { Viêm xoang, } \\
\text { chảy mũi }\end{array}$ & $\begin{array}{c}\text { Đau măt mă } \\
\text { nhìn mờ }\end{array}$ & $\begin{array}{c}\text { Nghe } \\
\text { kém }\end{array}$ \\
\hline 5 & 4 & 5 & 2 & 2 & 4 & 1 & 2 \\
\hline
\end{tabular}

Thời gian từ khi phát hiện triệu chứng tới khi nhập viện (tháng): 4 - 30
2. Hình ảnh học: Chụp CT: 5/5; Chụp MRI: 5/5. Hình ảnh $C T$ và $M R I$ cho thấy 2 ca u xâm lấn 
vào sọ não, 2 ca cho thấy u phá huỷ thành bên xoang bướm và xâm lấn xoang bướm, $3 \mathrm{ca} u$ xâm lấn vào vùng xoang hang và đỉnh ổ mắt . Hố thái dương và dưới thái dương 5 ca đều bị ảnh hưởng bởi u.

Chụp mạch não đồ DSA và làm tắc mạch khối u trước mổ: $5 / 5$

3. Phẫu thuật: Đường mổ đã thực hiện:

-Đường "lột găng" dưới rãnh lợi môi (Sublabial degloving): 1

-Đường trước tai dưới thái dương

(Preauricular subtemporal): 1

- Kết hợp: 3

1 bệnh nhân phải mổ lại lần 2 vì còn sót $u$ trong não.

Sử dụng máu trong và sau mổ: Không cần truyền máu: $3 / 5$ ca; 1 ca cần truyền nhiều nhất: 12 đơn vị hồng cầu

Trong khi mổ, 1 bệnh nhân chảy máu nhiều từ vị trí xoang hang được cầm máu được bằng Surgicel và spongel và keo sinh học, 1 bệnh nhân cần truyền máu nhiều trong và sau khi mổ vì u phức tạp và bệnh nhân có rối loạn đông máu đi kèm.

Các biến chứng sau mổ gồm 1 ca liệt dây thần kinh VII nhẹ. Không có biến chứng tử vong trong và sau mổ.

Theo dõi thực hiện sau 2 năm không có ca nào có tái phát u

\section{BÀN LUÂ̂N}

1. Về dịch tễ học. Tất cả bệnh nhân của chúng tôi là nam giới từ 13 tuổi đến 28 tuổi có thời gian bị bệnh kéo dài hay có trường hợp tình cờ được phát hiện khi đi chụp phim. Theo một số các tác giả khác thường tuổi bị bệnh của bệnh nhân là từ $15-19$ và không quá 20 [4], trong nghiên cứu này chúng tôi có 4 bệnh nhân trên 20 tuổi và lớn nhất là 28 tuổi, đây là điểm đáng lưu ý vì trong nghiên cứu chung về u xơ trước đây của chúng tôi ghi nhận tuổi bị bệnh của bệnh nhân cũng hầu hết là dưới 20 tuổi, cũng có khả năng vì các khối u xâm lấn vào trong não và các triệu chứng không rầm rộ cảnh báo cho bệnh nhân nên bệnhh nhân không quan tâm.

2. Các dấu hiệu lâm sàng. Triệu chứng nổi bật của nhóm nghiên cứu là nghẹt mũi, chảy máu mũi và nhức đầu xảy ra trên một bệnh nhân nam trẻ tuổi, nếu bệnh nhân thường bị chảy máu thì có biểu hiện niêm mạc nhợt, da xanh và tổng trạng phát triển không khoẻ mạnh. Khám trong mũu hoặc qua nội soi nhìn thấy khối u bề mặt nhẵn và có nhiều mạch máu, dễ chảy máu, bít kín vùng vòm mũi họng. Có 1 trường hợp u lớn chèn ép biến dạng mặt, ù tai chẩn đoán xác định muộn dẫn đến chậm trễ trong điều trị và 1 trường viêm xoang hàm, các trường hợp còn lại không bị ảnh hưởng đến xoang. Tuy nhiên, kích thước của khối u ở vòm mũi họng chỉ là tảng băng nổi vì nó không phải là toàn bộ kích thước khối $u$, một số trường hợp tiến triển của u trên lâm sàng có thể hoàn toàn im lặng thậm chí bệnh nhân chỉ có thể phát hiện bệnh nhờ vào chụp phim $[5,6,9]$

3. Hướng phát triển của $u$. Vị trí nguyên phát của JNA được cho là vùng chân bướm và lỗ bướm khẩu cái. Từ vị trí này u dễ dàng tiến vào phía trong vùng vòm mũi họng, mặt sau bên của xoang và phía ngoài hướng về hố chân bướm khẩu cái, khoảng $20 \%$ - 40\% bệnh nhân được chẩn đoán bệnh khi đang có $u$ xâm lấn vào nền so $[1,7,9]$; Y văn đề cập đến các đường xâm nhập vào sọ của u: (1) Chủ yếu là u từ hố chân bướm khẩu cái qua khe ổ mắt trên vào cạnh khoang yên ngựa của hố sọ giữa hoặc (2) từ xoang bướm ăn mòn trực tiếp thành xương phía trên vào hố yên / hoặc vào trong vào xoang hang, (3) từ ống bướm (pterigoid canal) lấn sâu vào đáy xương bướm và cánh lớn xương bướm, (4) từ hố dưới thái dương qua chỗ xương bị ăn mòn khuyết của nền hố sọ giữa và /hoặc những đường thông tự nhiên (hố tròn, hố bầu dục) sau đó chui vào hố sọ giữa, (5) Từ xoang sàng chui qua chỗ xương bị ăn mòn ở hố sọ trước $[2,3,4]$

Trong nghiên cứu của chúng tôi hâu hết bệnh nhân phát hiện u trong khoản thời gian rất ngắn trước khi nhập viện và u đã phát triển lan rộng nên chỉ có thể đánh giá vị trí tổn thương mà không thể xác định hướng phát triển của u

\section{Phân loại giai đoạn phát triển của JNA} Giai đoạn của u và chiến lược điều trị. Có nhiều các phân loại, bảng phân loại của Chandler dựa vào phân loại ung thư vùng mũi họng của AJCC, Phân loại của Sessions dựa vào bản chất và tiến triển của JNA, Radkowski thay đổi bảng của Sessions bằng chỉ ra hướng phát triển ra phía sau của u về chân bướm và lan vào ăn mòn vùng nền sọ. Andrews đã phân loại chính xác hơn các giai đoạn và vị trí của u trong sọ. Hiện nay, bảng phân loại của Andres đã được thực hiện áp dụng rộng rãi [10] Phân giai đoạn của u dựa trên CT và MRI đã được thực hiện đối với u xơ mạch vòm mũi họng JNA, tuỳ thuộc vào sự liên quan của u tới khoang giải phẫu nào của cớ thể cũng như sự nguy hiểm tiềm năng sau phẫu thuật và khả nẳng tái phát, như vậy, chúng rất có ích cho việc lựa chọn đường phẫu thuật. Chúng tôi cũng phân loại dựa vào bảng phân loại 
của Andres vì phương pháp này cho phép phân loại rõ ràng chính xác những khối u ở vùng hố thái dương và có xâm lấn vào não và như vậy những u trong nghiên cứu này của chúng tôi là nằm trong nhóm IIIB và IV. VIệc này sẽ cho phép chúng tôi quyết định chọn lựa đường phẫu thuật.

5. Vai trò của CT scan, MRI và chụp mạch máu DSA. Hình ảnh của $C T$ và $M R I$ là chủ yếu để chẩn đoán và tiên lượng bệnh cũng như xác định giai đoạn của u trước khi mổ. Cả 2 đóng vai trò hỗ trợ cho nhau một cách nhuân nhuyễn, chính xác. MRI có ưu điểm là cho thây những thay đổi đặc biệt trưng ở các mô mềm, đặc biệt khi cân xem xét những u đã xâm lấn vào trong sọ hay vào ổ mắt. Đó cũng là yếu tố quyết định gíup đánh giá xem u có liên quan đến những cấu trúc quan trọng khác trong sọ như động mạch cảnh trong, xoang hang, tuyến yên, hay màng cứng $[2,8]$.

CT Scan cho phép đánh gía tổn thương của xương đăc biệt vùng chân bướm, các phân xương xốp của cánh lớn xương bướm, các thành xoang và xương vùng nền sô, hay thấy các lỗ thông tự nhiên vùng nền sọ (lồ tròn, lỗ bầu dục) cũng như các khe bị rộng ra. Nêú thây hình ảnh khối u đa thuỳ, cấu trúc mô mêm không có bao ở vùng hố chân bướm đẩy ép thành sau xoang hàm ra trước (dấu hiệu Holman-Miller) sẽ là dấu hiệu điển hình của JNA[3,8].

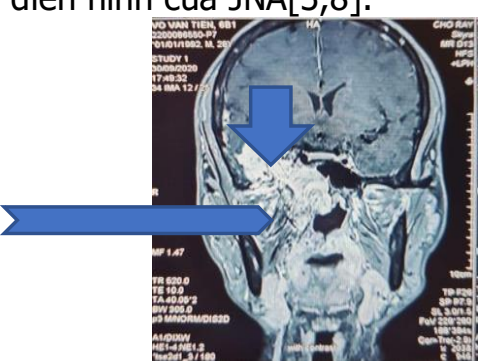

Hinh 2: Khôi u lớn vùng vòm mũi họng và hố dưới thái dương (mũi tên đuôi nheo), nên sọ bi ăn mòn u xâm lấn vào nội sọ cạnh xoang hang (mũi tên ngắn)

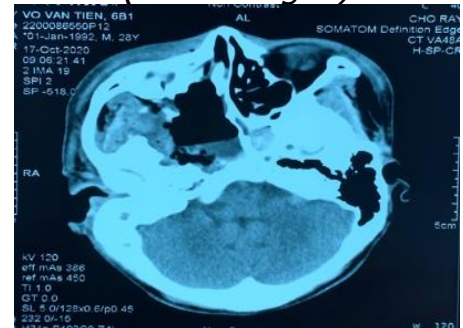

Hình 3: Sau khi mổ u

Xâm lấn vào não của JNA thường đẩy màng não hoặc một phân dính vào đó. Tuy nhiên, hình ảnh học sẽ không thể giúp xác định được quan hệ giữa u và màng não, Nếu u xuyên qua màng não thì sẽ không thấy có lớp đệm giữa cấu trúc u và có cấu trúc thân kinh mạch máu. Hình ảnh U bao quanh động mạch cảnh trong có thể dẫn tới giải thích không chính xác giai đọan hay liên quan đến xoang hang của u [9]. Trong khi phẫu thuật có 1 trường hợp chúng tôi thấy được màng não bộc lộ.

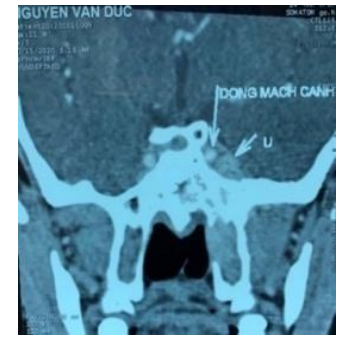

Hình 4: U xâm lấn vùng xoang hang và quanh đông mach cảnh trong

Chụp DSA và làm tắc mạch trước mổ được thực hiện trên cả 5 bệnh nhân cho thấy hâu hết các nhánh nuôi u đâu xuất phát từ động mạch hàm trong. Các nhánh động mạch khác như màng não, động mạch mắt hay bướm của động mạch cảnh trong đặc biệt nếu $u$ to hoặc tiến triển xa (ví dụ : liên quan đến xoang bướm có thể kèm theo với máu cung cấp từ các nhánh của động mạch cảnh trong đoạn xoang hang). Xuất hiện của mạch máu phân nhu mô não kèm theo nhánh nuôi phu khối u có thể là dấu hiêu của u đã xuyên vào não $[2,4]$. Ngoài ra còn có những nhánh nhỏ khác trực tiếp từ động mạch cảnh ngoài và động mạch cảnh trong cùng bên mà chúng ta cân chú ý vì đa số những nhánh mạch nuôi phụ rất nhỏ và không gây chảy máu nhiều trong khi mổ, tuy nhiên nếu là nhánh động mạch đoạn ngay trước khi chia nhánh động mạch mắt thì khi làm tắc mạch có thể gây mù cho bệnh nhân $[5,6]$. Nếu chẩn đoán còn nghi ngờ thì việc sinh thiết lại cho bệnh nhân theo chúng tôi chỉ nên thực hiện sau khi đã gây mê bệnh nhân và sẵn sàng cho cuộc mổ lấy u cũng như đa số trường hợp làm tắc mạch sẽ giúp giảm chảy máu đáng kể trong khi phẫu thuật đã được ghi nhân, tuy nhiên điều này không phải bao giờ cũng như vây. Một số tác giả không thống nhất việc làm tắc mạch vì cho rằng việc này sẽ làm tăng nguy cơ lấy không hết u đặc biệt khi u xâm lấn sâu. Andrade và cộng sự không hề làm tắc mạch trước phẫu thuật cho dù là giai đoạn III hay IV.

6. Về phẫu thuật. Với những JNA ngoài sọ, việc điêu trị luôn là phẫu thuật cắt $u$. Việc này sẽ phụ thuộc vào phẫu thuât viên, cách u xâm lấn vào trong sọ. Đường phẩu thuật có thể là từ 
phía trước, phía dưới, hay từ phía bên. Từ bên dưới có thể xuyên qua khẩu cái và xuyên họngmiệng. Đường phía trước gồm có qua mũi, mở xoang hàm Lefort I, Đường mổ lột găng. Đường bên xuyên qua hố dưới thái dương.

Phẫu thuật nội soi được áp dụng đã mang lại những ưu điểm so với những kỹ thuật kinh điển bao gồm không rạch đường mũi ngoài, cải thiện tỷ lệ tái phát cũng như có tỷ lệ biến chứng thấp $[5,6]$. Đường mố xuyên qua mũi cắt u có hạn chế đối với u xâm lấn trong vùng nền sọ giữa, trong sọ hay phía bên vùng hố dưới thái dương. Trong nhiều phương thức điều trị JNA chui vào sọ thì phẫu thuật nhổ bỏ khối u (extirpation) và tia xạ có vẻ tỏ ra hiệu quả $[5,7,9]$. Như vậy, phương pháp tốt nhất điều trị JNAvấn có những quan điểm khác nhau khi so sánh những nguy cơ của phẫu thuật với những biến chứng hay khả năng tái phát của xạ trị. Một số tác giả chọn phương án chỉ lấy phần u ngoài sọ và chửa lại phân u trong sọ để theo dõi vì khối u có khả năng ổn định không phát triển nữa sau quá trình theo dõi lâu dài $[5,9]$. Một số khác đề xuất nễu u còn sót trong não thì dùng xạ trị hay tia dao Gamma đặc biệt ở những vị trí như xoang hang hay giao thoa thị giác. Nghiên cứu của Chandler xạ trị với u giai đoạn III hay IV của JAF đạt hiệu quả $85 \%-91 \%$. Tuy nhiên, có rất nhiêu các biến chứng của phương pháp này được ghi nhận gồm $\mathrm{u}$ ác tính vùng đầu cổ, cườm mắt, suy tuyến hạ đồi, loạn dưỡng xương, hoặc bệnh lý thần kinh. Với một số tác giả khác thì xạ trị có hiệu quả và không có biến chứng

Chúng tôi sử dụng đường phía trước xuyên xoang hàm hay qua đường "lột găng" cho phép tiếp cận u xâm lấn ở vùng chẩn bướm khẩu cái, xoang cạnh mũi và phần phía trong của xoang hang, không dùng đường cạnh bên mũi vì để lại sẹo và vấn đề thẩm mỹ lớn cho bệnh nhân. Đường xuyên hố dưới thái dương cho phép bộc lộ rộng hố dưới thái dương và rất thuận tiện cho việc lấy những khối u lan rộng sang phía bên cũng như xâm lấn vào sọ phía bên ngoài của xoang hang. Hầu hết chúng tôi lấy u một thì khi kết hợp giữa 2 đường mổ này và nội soi. 1 trường hợp phải mổ lại lần 2 lây u trong não vì còn sót u sau lần mố 1 . Nếu u bao quanh động mạch cảnh trong hết $3 / 4$ đường kính thì chúng tôi rất thận trong vì khả năng biến chứng và chảy máu nhiều không kiểm soát được. Để lấy u từ đường trong mũi, chúng tôi thường dùng thìa Taptas (dùng cắt amidan) luồn đẩy u và kết hợp dùng một pince gắp $u$ to kéo nhổ (extirpation) u theo chiều sau ra trước và từ trên xuống dưới.
Trong khi nhổ u phải chú ý lượng máu chảy, dấu hiệu sinh tồn xem các mạch máu lớn có bi thương tổn không. Việc cắt nhỏ lấy từng phần dễ có nguy cơ bỏ sót $u$. Sau mổ nên kiểm tra $U$, thường các thuỳ của u non, rất mềm, màu trắng ngà và dễ dàng lấy ra, trái ngược với những phần u "già" màu sậm, dai.

Đường mổ Trước tai dưới thái dương chúng tôi nhận thấy rất thuận tiện cho việc bộc lộ rộng phẫu trường để thao tác phẫu thuật và lẩy u ở vùng hố dưới thái dương cũng như vùng xoang hang và hố sọ giữa.

Với những khối u xâm lấn vào trong sọ não và xoang hang chúng tôi phải sử dụng đường kết hợp. Việc mở sọ qua xương thái dương đã cho phép bộc lộ rõ ràng động mạch cảnh, xoang hang, khe ổ mắt trên. Có thể nói việc thành công của ca phẫu thuật sẽ tuỳ thuộc rất nhiều vào kinh nghiêm của phấu thuật viên, chọn lựa bệnh nhân, hình ảnh hoc và làm tắc mach trước khi mổ cũng như phối hợp của 2 kíp phẫu thuật tai mũi họng và ngoại khoa thần kinh.

Số lượng máu mất trung bình là 300-400 cc nên chúng tôi không phải truyền máu trong khi mổ, có 1 trường hợp chảy máu do u lớn xâm lấn nhiêu thì chúng tôi phải dùng một số lượng máu lớn trong và sau mổ.

Vai trò của nội soi trong việc phẫu thuật JNA đã được ghi nhận trong thời gian gần đây vì hiệu quả thẩm mỹ, quan sát u và giới hạn rõ ràng, cầm máu chính xác. Tuy nhiên, với những u nằm ở phía bên vùng hố dưới thái dương thì nội soi bị hân chế mặc dù một số tác giả công bố kết quả vẩn hiệu quả $[1,4]$. Chúng tôi đã thực hiện kêt hợp nội soi cả trong phẫu thuật nội soi qua mũi xoang cũng như qua đường mổ hở xuyên hố dưới thái dương cho thấy rất an toàn và hiệu quả.

\section{KẾT LUẬN}

U xơ mạch vòm mũi họng có đặc điểm thường lan rộng ra ngoài vùng vòm mũi họng và xâm lấn vào não hay xoang hang gây nên những biến chứng nặng nề nhưng các triệu chứng có thể bị lẫn hay không dễ dàng nhận ra xảy ra. Cần chú ý nếu u vòm mũi họng xảy ra trên bệnh nhân giới nam, tuổi thiếu niên với các triệu chứng nghẹt mũi, thỉnh thoảng chảy máu mũi, ù tai v.v.

Hình ảnh học cho phép đánh giá chính xác giai đoạn, mức độ xâm lấn rộng vào các mô xung quanh của u cũng như mức độ phá hủy xương có liên quan ở vùng nền sọ hay xoang hang.

Điều trị phẫu thuật vẫn còn là phương pháp chủ yếu, xạ trị dành cho những trường hợp 
không thể phẫu thuật được. Đường phẫu thuật rãnh lợi môi qua mũi (hay đường "lột găng") cùng với đường mổ trước tai dưới thái dương sử dụng riêng lẻ hay phối hợp giúp chúng tôi áp dụng được cho đa số các trường hợp u tiến triển rộng vào trong nội sọ.

Mặc dù đã có những kỹ thuât mới được áp dụng nhưng tỷ lệ tái phát sau mổ của u xâm lấn vào sọ vẫn được ghi nhận từ $15-50 \%$. Trong nghiên cứu này chúng tôi chưa gặp tái phát cũng như những biến chứng và tử vong. Cần nhắc lại: nếu một bệnh nhân nam tuổi dậy thì có dấu hiệu nghẹt mũi, chảy máu mũi thì cần sớm được khám bởi các bác sĩ chuyên khoa Tai Mũi Họng.

\section{TÀI LIÊU THAM KHẢO}

1. Snyderman C.H., Pant H.: Endoscopic management of vascular sinonasal tumors, including angiofibroma. Otolaryngol. Clin. North Am., 2016; 49(3): 791-807.

2 Charkaborty S., Ghoshal S., Patil V.M,. Oinam A.S., Sharma S.C.: Conformal radiotherapy in the treatment of advanced juvenile nasopharygeal angiofibro- ma with intracranial extension: an institutional experience. Int. J. Radiation Oncology
Biol. Phys., 2011; 80: 1398-1404.

3. Blount A., O'Riley K., Woodworth B.A.: Juvenile nasopharyngeal angiofibroma. Otolaryngol. Clin. North Am., 2011; 44: 989-1004.

4. Balcerzak J., Gotlib T., Hamera M., OsuchWójcikiewicz E., Niemczyk K.: Angiofibroma juvenile evolution of surgical management. Otolaryngol. Pol. 2011; 65(5 Suppl): 12-16.

5. Danesi G., Panciera D.T., Harvey R., Agostinis C.: Juvenile nasopharyngeal an- giofibroma: evaluation and surgical management of advanced disease. Otola- ryngol Head Neck Surg., 2008; 138: 581-586.

6. Trânn mInh Trường: Môt số kinh nghiệm điều trị phẫu thuật u xơ vòm mũi họng . Tập san Hội nghi KHKT năm 2007 ĐHYD

7. Bales C., Kotapka M., Loevner L.A., Al-Ravi M., Weinstein G. et al.: Craniofacial resection of advanced juvenile nasopharyngeal angiofibroma. Arch. Oto- laryngol. Head. Neck. Surg., 2002; 128: 1071-1078.

8. Schick B., Kahle G.: Radiological findings in angiofibroma. Acta. Radiol., 2000; 41: 585-593.

9. Bales C., Kotapka M., Loevner L.A., Al-Ravi M., Weinstein G. et al.: Craniofacial resection of advanced juvenile nasopharyngeal angiofibroma. Arch. Oto- laryngol. Head. Neck. Surg., 2002; 128: 1071-1078.

\title{
ĐÁNH GIÁ TƯƠ'NG QUAN GIỮA BÊ̂NH COVID-19 VÀ Độ BAO PHỦ TIÊM VẮC XIN Ở TỈNH ĐẮK LẮK, NĂM 2021
}

\author{
Nguyễn Ngọc Như Khuêi , Vũ Thị Quỳnh Hậu², Nguyễn Hữu Huyên ${ }^{3}$
}

\section{TÓM TẮT}

Nghiên cứu này nhằm đánh giá mối tương quan giữa bệnh COVID-19 và độ bao phủ tỷ lệ tiêm vắc xin mũi 1 , mũi 2 tai tỉnh Đắk Lắk. Bằng phương pháp nghiên cứu hồi cứu mô tả có phân tích số liệu thu thập trên các báo cáo nhanh hàng ngày của Sở $Y$ tế Đắk Lắk và báo cáo đô bao phủ tiêm mũi 1 , mũi 2 vắc xin theo huyện, thị xã̃, thành phố. Kết quả cho thấy, không có sự tương quan giữa độ bao phủ tỷ lệ tiêm mũi 1 , mũi 2 vắc xin và số ca mắc mới theo thời gian trước và sau 7,14 và 21 ngày. Không có tương quan giữa độ bao phủ tỷ lệ tiêm mũi 1 , mũi 2 vắc xin và số ca mắc mới theo ngày toàn tỉnh. Có sự tương quan giữa độ bao phủ tỷ lệ tiêm mũi 1 , mũi 2 vắc xin và mức độ bệnh: không triệu chứng và triệu chứng nhẹ. Có tương quan giữa tỷ lệ tiêm vắc xin mũi 1 và số bệnh nhân ra viên theo ngày toàn tỉnh.

Tư khóa: CỎVID-19, Vắc xin, Tương quan, Đắk Lắk.

${ }^{1}$ Bênh viện Đa khoa Vùng Tây Nguyên

${ }^{2}$ Trung Tâm Y tế Thành phố Buôn Ma Thuột

${ }^{3}$ Sở Y tế tỉnh Đăk Lăk

Chịu trách nhiệm chính: Nguyễn Ngọc Như Khuê

Email: nhukhuenguyen@gmail.com

Ngày nhận bài: 16.9.2021

Ngày phản biên khoa hoc: 8.11.2021

Ngày duyệt bài: 22.11.2021

\section{SUMMARY \\ EVALUATE THE CORRELATION BETWEEN COVID-19 DISEASE AND COVERAGE OF VACCINATION RATES IN DAK LAK PROVINCE, 2021}

This study aims to evaluate the correlation between COVID-19 disease and coverage of vaccination rates of 1st and 2nd doses in Dak Lak province. Using retrospective descriptive study with analysis of data collected on daily quick reports of Dak Lak Health Service and reported coverage of 1st and 2nd dose vaccines by district, town, and city. The results showed that there was no correlation between the coverage rate of 1st dose, 2nd dose of vaccine and the number of new cases over time before and after 7, 14 and 21 days. There is no correlation between coverage rate of 1st dose, 2nd dose of vaccine and the number of new cases per day in the province. There is a correlation between the coverage rate of 1st dose, 2nd dose of vaccine and clinical leval of disease: asymptomatic and mild symptoms. There is a correlation between the rate of 1st dose vaccination and the number of patients discharged from hospital by day in the whole province. Lak. 